\title{
Qualidade de goiaba-serrana em resposta à temperatura de armazenamento e ao tratamento com 1-metilciclopropeno
}

\author{
Cassandro Vidal Talamini do Amarante(1), Cristiano André Steffens ${ }^{(1)}$, Jean Pierre Henri Joseph Ducroquet( ${ }^{(2)}$ \\ e Alexandre Sasso ${ }^{(1)}$
}

(1)Universidade do Estado de Santa Catarina, Centro de Ciências Agroveterinárias, Departamento de Agronomia, Caixa Postal 281 CEP 88520-000 Lages, SC. E-mail: amarante@cav.udesc.br, steffens@cav.udesc.br, sassos13@yahoo.com.br (2)Empresa de Pesquisa Agropecuária e Extensão Rural de Santa Catarina S.A., Estação Experimental de São Joaquim, Caixa Postal 81, CEP 88600-000 São Joaquim, SC. E-mail: ducroquet@epagri.rct-sc.br

Resumo - Os objetivos deste trabalho foram caracterizar a fisiologia e avaliar os efeitos da temperatura e da aplicação de 1-metilciclopropeno (1-MCP) na qualidade pós-colheita de frutos de goiaba-serrana (Acca selowiana), em acessos do banco ativo de germoplasma da Empresa de Pesquisa Agropecuária e Extensão Rural de Santa Catarina. Os frutos foram colhidos na maturação comercial. Os genótipos Brasil (acesso 387) e Uruguai (acesso 454) foram avaliados quanto ao comportamento respiratório e de produção de etileno a $20^{\circ} \mathrm{C}$, e taxas respiratórias e alterações na cor da casca a $0,5,10,20$ e 30 ${ }^{\circ} \mathrm{C}$. O genótipo Brasil (acesso 242) foi avaliado quanto ao amadurecimento a $4^{\circ} \mathrm{C}$, após tratamento com 1-MCP $(0,500$ e $1.500 \mathrm{ppb})$. Os genótipos Brasil (acesso 387) e Uruguai (acesso 454) apresentaram comportamento climatérico, com picos de produção de etileno e de taxa respiratória aos 8 e 12 dias de armazenamento a $20^{\circ} \mathrm{C}$, respectivamente. Não houve diferença significativa entre as taxas respiratórias e de produção de etileno entre os genótipos, nessa temperatura. Houve aumento substancial na taxa respiratória em ambos os genótipos, com o aumento de 0 para $30^{\circ} \mathrm{C}$, com coeficiente metabólico de 3,5 aproximadamente. Com o aumento na temperatura, houve maior alteração na cor verde da epiderme, em frutos do tipo Brasil, e maior escurecimento da epiderme, em frutos do tipo Uruguai. Frutos do genótipo Brasil (acesso 242), tratados com 1-MCP e armazenados a $4^{\circ} \mathrm{C}$, apresentaram retardamento no amadurecimento.

Termos para indexação: Acca sellowiana, amadurecimento, feijoa, genótipo, etileno.

\section{Fruit quality of feijoas in response to storage temperature and treatment with 1-methylcyclopropene}

\begin{abstract}
The objectives of this work were to characterize the postharvest physiology and to evaluate the effects of temperature and treatment with 1-methylcyclopropene (1-MCP) on the postharvest quality of fruits of feijoa (Acca selowiana) accessions from the germplasm bank of Empresa de Pesquisa Agropecuária e Extensão Rural de Santa Catarina. Fruits were harvested at commercial maturity. The genotypes Brasil (accession no. 387 ) and Uruguai (accession no. 454) were evaluated for respiration and ethylene production at $20^{\circ} \mathrm{C}$, and respiration rates and skin color alterations at $0,5,10,20,30^{\circ} \mathrm{C}$. The genotype Brasil (accession no. 242) was evaluated for ripening at $4^{\circ} \mathrm{C}$, after treatment with 1-MCP $(0,500$ and 1,500 ppb). Brasil (accession no. 387) and Uruguai (accession no. 454) exhibited a climacteric pattern, with a peak of ethylene evolution and respiration rate at the $8^{\text {th }}$ and $12^{\text {th }}$ days of storage at $20^{\circ} \mathrm{C}$, respectively. There was no significant difference for respiration rates and ethylene evolution between these genotypes at this temperature. There was a substantial increase of respiration rate in both genotypes with the increase in temperature from 0 to $30^{\circ} \mathrm{C}$, with a metabolic coefficient of approximately 3.5. With the increase in temperature, fruits of the genotype Brasil showed the greatest change of skin green color, while fruits of the genotype Uruguai exhibited the greatest darkening of skin. Feijoa fruits of genotype Brasil (accession no. 242) had delayed ripening when treated with 1-MCP and stored at $4^{\circ} \mathrm{C}$.
\end{abstract}

Index terms: Acca sellowiana, ripening, feijoas, genotype, ethylene.

\section{Introdução}

Frutos de espécies nativas com propriedades nutracêuticas e sensoriais como cor, sabor e aroma, podem ser explorados comercialmente para o consumo in natura. A região Sul do Brasil possui várias espécies frutíferas nativas, da família Myrtaceae, com potencial para a exploração comercial, das quais se destaca a 
goiabeira-serrana [Acca sellowiana (Berg.) Burret., sinônimo Feijoa sellowiana Berg.].

A goiabeira-serrana apresenta dois centros de dispersão, aos quais correspondem duas variedades botânicas diferentes: o primário, nas serras do Nordeste do Rio Grande do Sul e de Santa Catarina, correspondente à variedade Brasil; e o secundário, nas serras do Sudeste do Rio Grande do Sul e Norte do Uruguai, correspondente à variedade Uruguai (Ducroquet et al., 2000). O genótipo Brasil ocorre com maior freqüência em áreas com altitudes superiores a 800 m, em formações de bosques e matas de araucária (Legrand \& Klein, 1977; Mattos, 1990; Ducroquet et al., 2000).

$O$ fruto da goiabeira-serrana, classificado como pseudo-fruto do tipo pomo, é uma baga com formato oblongo, polpa de cor gelo, e casca que pode ser lisa, semi-rugosa ou rugosa. A goiaba-serrana pode apresentar diâmetro de 3-5 cm, comprimento de 4-10 cm, peso de 20-250 g (Mattos, 1990) e rendimento de polpa de $15-50 \%$ (Degenhardt et al., 2003). O fruto - também conhecido como feijoa, goiaba-do-mato ou goiaba-da-serra - apresenta sabor doce-acidulado e aroma penetrante, e é pouco conhecido, ainda, no mercado brasileiro (Ducroquet et al., 2000). A goiabaserrana contém $25-30 \mathrm{mg}$ de vitamina $\mathrm{C} / 100 \mathrm{~g}$ (Hoffmann et al., 1994; Degenhardt et al., 2003) e apresenta atividade antibactericida, antioxidante e antialérgica, além de flavonóides, que promovem a atividade imunológica, e auxilia no controle de processos inflamatórios (Basile et al., 1997; Vuotto et al., 2000). Além do consumo in natura, os frutos podem ser processados e utilizados na produção de sucos, geléias, sorvetes e bebidas (Mattos, 1990).

Apesar de não apresentar cultivo expressivo no Brasil, a goiaba-serrana já é comercializada nos Estados Unidos e Europa, com cultivares desenvolvidas principalmente na Nova Zelândia e Estados Unidos (Ducroquet et al., 2000), a partir de material genético coletado no Uruguai (Thorp, 1988). Em Santa Catarina, esta espécie vem sendo pesquisada desde 1986, pela Empresa de Pesquisa Agropecuária e Extensão Rural de Santa Catarina S.A. (Epagri), com o objetivo de selecionar genótipos superiores e desenvolver um sistema de produção que permita seu cultivo em escala comercial. Testes de degustação, realizados em Santa Catarina, mostraram que mais de $90 \%$ das pessoas consideraram o sabor e o aroma da fruta como bons ou ótimos (Barni et al., 2004). Isto evidencia o potencial de cultivo comercial de goiabeira-serrana, em regiões de altitude, no Sul do Brasil.

A casca da goiaba-serrana é firme, o que proporciona facilidades, principalmente no transporte após a colheita. No entanto, o tempo de conservação em câmara fria é limitado, e corresponde a aproximadamente um mês a $4^{\circ} \mathrm{C}$, seguido de cinco dias de vida-de-prateleira a $20^{\circ} \mathrm{C}$ (Thorp \& Klein, 1987). A armazenagem por longos períodos compromete a qualidade dos frutos, que apresentam redução no sabor associada à redução da acidez e da concentração de sólidos solúveis, bem como dos teores de vitamina C (Hoffmann et al., 1994).

As bases fisiológicas do processo de amadurecimento dos frutos de goiabeira-serrana não são bem conhecidas, o que torna difícil o estabelecimento de estratégias de preservação de sua qualidade pós-colheita. Aclassificação de goiaba-serrana como fruto climatérico ou não climatérico, bem como a caracterização das taxas respiratórias e do amadurecimento, em resposta à temperatura de armazenamento, não foram estudados nos genótipos Brasil e Uruguai, especialmente em termos comparativos.

O objetivo deste trabalho foi caracterizar a fisiologia e avaliar os efeitos da temperatura de armazenamento e do tratamento com 1-metilciclopropeno, na preservação da qualidade pós-colheita de frutos de dois genótipos de goiaba-serrana.

\section{Material e Métodos}

Foram utilizados dois acessos de goiaba-serrana, pertencentes à coleção de genótipos da Epagri-Estação Experimental de São Joaquim: o acesso 387, do genótipo Brasil, e o acesso 454, do genótipo Uruguai.

Os frutos dos dois acessos da goiabeira-serrana foram colhidos na maturação comercial - correspondente ao ponto de abscisão do fruto, imediatamente após a queda no chão - e imediatamente transportados para o Laboratório de Fisiologia e Tecnologia Pós-Colheita, do Centro de Ciências Agroveterinárias (CAV), da Universidade do Estado de Santa Catarina (Udesc), em Lages, SC.

A caracterização da fisiologia pós-colheita foi realizada nos frutos dos dois genótipos de goiabaserrana, que foram armazenados em estufas BOD a $20 \pm 2^{\circ} \mathrm{C}(90-95 \%$ UR) e avaliados quanto às taxas 
respiratórias e de produção de etileno, em intervalos de 2 dias, durante 24 dias. As quantificações de $\mathrm{CO}_{2}$ e etileno foram feitas em sistema fechado, em que cinco frutos foram acondicionados em embalagens de plástico $(1.100 \mathrm{~mL})$, durante $30 \mathrm{~min}$, antes da coleta das amostras de gases. As amostras de $1 \mathrm{~cm}^{3}$ foram extraídas através de um septo com seringa hipodérmica graduada e injetadas em um cromatógrafo a gás Varian (modelo CP 3800), equipado com um metanador, detector de ionização de chama e coluna Porapaq N (80 a 100 mesh). As temperaturas do forno, do detector, do metanador e do injetor foram de $45,120,300$ e $110^{\circ} \mathrm{C}$, respectivamente. Os fluxos de $\mathrm{N}_{2}, \mathrm{H}_{2}$ e ar utilizados foram de 70,30 e $300 \mathrm{~mL} \mathrm{~min}^{-1}$, respectivamente. As taxas respiratórias (nmol de $\mathrm{CO}_{2} \mathrm{~kg}^{-1} \mathrm{~s}^{-1}$ ) e de evolução de etileno ( $\mathrm{nmol} \mathrm{de} \mathrm{C}_{2} \mathrm{H}_{4} \mathrm{~kg}^{-1} \mathrm{~s}^{-1}$ ) foram expressas segundo o sistema internacional de unidades.

$\mathrm{O}$ experimento seguiu o delineamento inteiramente casualizado, com quatro repetições, com cinco frutos cada um, para cada genótipo de goiaba-serrana. Os dados foram submetidos à análise de medidas repetidas, para se avaliarem os efeitos de tempo e de genótipo nas taxas respiratórias e de produção de etileno, com o programa SAS (SAS Institute, 2002).

Os frutos dos dois acessos foram armazenados em estufa BOD a $0,5,10,20$ e $30^{\circ} \mathrm{C}(90-95 \%$ UR) e as taxas respiratórias foram avaliadas 24 horas após a estabilização das diferentes temperaturas, conforme descrito no experimento anterior, para quantificação do coeficiente metabólico $\left(\mathrm{Q}_{10}\right)$. Foram feitas, também, avaliações de cor da casca, na região equatorial dos frutos (duas leituras por fruto, em lados opostos), em intervalos de dois dias, durante o armazenamento (entre 12 e 46 dias, para as temperaturas de $30 \mathrm{e} 0^{\circ} \mathrm{C}$, respectivamente), com o auxílio de um colorímetro Minolta CR 400, pela quantificação da luminosidade ('lightness', L) e do ângulo 'hue' $\left(\mathrm{h}^{\circ}\right)$.

$\mathrm{O}$ experimento seguiu o delineamento inteiramente casualizado, com os tratamentos em arranjo fatorial 2x5 (dois genótipos e cinco temperaturas), com três repetições, com quatro frutos cada. Os dados foram submetidos à análise de variância e a ajustes de regressões lineares e não lineares com o programa SAS (SAS Institute, 2002).

Frutos do tipo Brasil (acesso 242) de goiabeiraserrana foram colhidos na maturação comercial, conforme descrito anteriormente, e tratados com 1-metilciclopropeno (1-MCP), nas doses de 0, 500 e $1.500 \mathrm{ppb}$. As concentrações de 1-MCP foram obtidas com o produto SmartFresh diluído em água, e a aplicação foi realizada em câmaras herméticas, com volume de $1,2 \mathrm{~m}^{3}$, durante 8 horas, a $20 \pm 2^{\circ} \mathrm{C}(80 \pm 5 \%$ de UR).

Após a aplicação de 1-MCP, os frutos foram armazenados a $4 \pm 1{ }^{\circ} \mathrm{C} / 90 \pm 5 \%$ UR e avaliados, após 15 e 30 dias de armazenamento refrigerado, quanto aos atributos de textura - força para ruptura da epiderme, força para penetração da polpa e resistência do fruto à compressão e ao corte -, firmeza de polpa, acidez titulável (AT), sólidos solúveis (SS) e cor da epiderme.

Os atributos de textura foram analisados com um texturômetro eletrônico TAXT-plus (Stable Micro Systems Ltda.), na região equatorial dos frutos (uma medição por fruto). Para a quantificação da força necessária para o rompimento da epiderme e penetração na polpa, foi utilizada uma ponteira PS2, com $2 \mathrm{~mm}$ de diâmetro, introduzida na polpa à profundidade de $8 \mathrm{~mm}$, com velocidades pré-teste, teste e pós-teste de 10,1 e $10 \mathrm{~mm} \mathrm{~s}^{-1}$, respectivamente. A resistência do fruto à compressão foi determinada com uma plataforma $\mathrm{P} / 75$, com $75 \mathrm{~mm}$ de diâmetro, em velocidades de pré-teste, teste e pós-teste de 10, 0,5 e $30 \mathrm{~mm} \mathrm{~s}^{-1}$, respectivamente. A plataforma exerceu força de compressão até a deformação de $3 \mathrm{~mm}$ na superfície do fruto. A resistência ao corte, na região equatorial dos frutos (uma medição por fruto) foi efetuada com uma ponteira tipo guilhotina, com velocidades de pré-teste, teste e pós-teste de 15,5 e $30 \mathrm{~mm} \mathrm{~s}^{-1}$, respectivamente, e com profundidade de corte de $20 \mathrm{~mm}$.

A firmeza da polpa (N) foi quantificada com um penetrômetro Effegi, modelo de bancada, munido de ponteira com 7,9 mm de diâmetro. Foram efetuadas duas leituras, em lados opostos da região equatorial dos frutos, após a remoção de uma pequena área da casca.

Os valores de AT (percentagem de ácido cítrico) foram obtidos por titulometria de amostra de suco dos frutos $(10 \mathrm{~mL}$ de amostra, diluída com $90 \mathrm{~mL}$ de água destilada), com solução de hidróxido de sódio $0,1 \mathrm{~N}$ até pH 8,1 e fenolftaleína como indicador.

Os teores de SS ( ${ }^{\circ}$ Brix) foram determinados com refratômetro manual (Abbe Atago) no suco extraído, conforme descrito para a AT, com correção da leitura para a temperatura de $20^{\circ} \mathrm{C}$.

A determinação da cor da epiderme foi efetuada por meio da quantificação dos atributos de $\mathrm{L} e \mathrm{~h}^{\mathrm{o}}$ da epiderme, como descrito no experimento anterior.

Pesq. agropec. bras., Brasília, v.43, n.12, p.1683-1689, dez. 2008 
O experimento seguiu o delineamento inteiramente casualizado, com quatro repetições de 10 frutos. Os dados foram submetidos à análise de variância, e o efeito de dose de 1-MCP, sobre os atributos de amadurecimento, foi avaliado aos 15 e 30 dias de armazenamento a $4 \pm 1^{\circ} \mathrm{C}$ e analisado por meio de contrastes ortogonais polinomiais (linear e quadrático), em níveis de significância de 5,1 e $0,1 \%$, com o SAS (SAS Institute, 2002).

\section{Resultados e Discussão}

Ambos os genótipos de goiaba-serrana apresentaram comportamento climatérico, com picos de produção de etileno e $\mathrm{CO}_{2}$ aos 8 e 12 dias de armazenamento a $20^{\circ} \mathrm{C}$, respectivamente (Figura 1). A análise de medidas repetidas mostrou que o aumento nas taxas respiratórias e de produção de etileno, durante o climatério, em ambos os genótipos, foi significativo $(p<0,0001)$, e não houve diferença significativa entre essas variáveis, entre os tipos Brasil e Uruguai, durante o período pós-colheita.

$\mathrm{Na}$ avaliação do efeito da temperatura sobre as taxas respiratórias de genótipos de goiaba-serrana, foi observado um comportamento sigmoidal (Figura 2). O tipo Brasil apresentou grande incremento na respiração, com o aumento da temperatura entre 0 e $20^{\circ} \mathrm{C}$, seguido de pequeno aumento entre 20 e $30^{\circ} \mathrm{C}$. O tipo Uruguai apresentou aumento praticamente linear entre 0 e $30^{\circ} \mathrm{C}$, tendo atingido taxas respiratórias similares ao tipo Brasil na maior temperatura $\left(30^{\circ} \mathrm{C}\right)$.

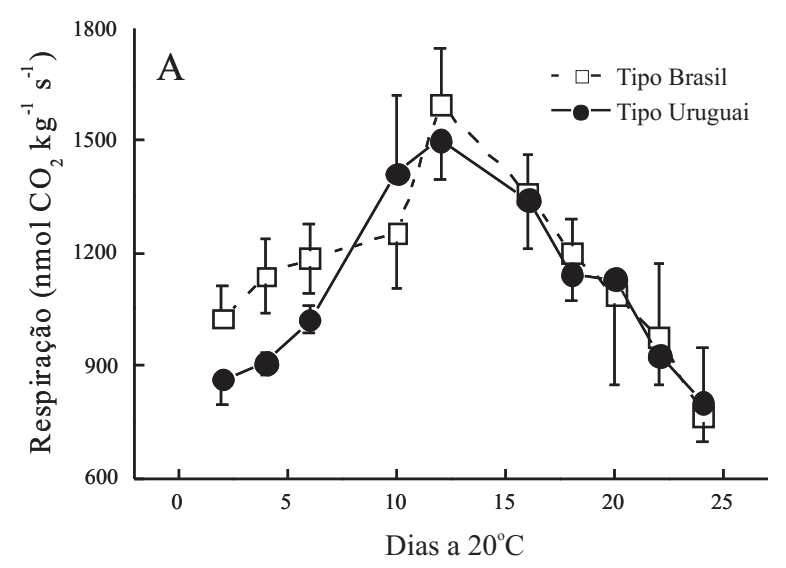

Figura 1. Taxas respiratórias (A) e de produção de etileno (B) de goiabeira-serrana dos tipos Brasil (acesso 387) e Uruguai (acesso 454), durante o armazenamento a $20^{\circ} \mathrm{C}$. Os símbolos representam valores médios \pm erro-padrão da média $(\mathrm{n}=4)$.

Pesq. agropec. bras., Brasília, v.43, n.12, p.1683-1689, dez. 2008
Segundo Taiz \& Zeiger (2002), a elevação da temperatura para valores próximos a $30^{\circ} \mathrm{C}$ aumenta a demanda respiratória por $\mathrm{O}_{2}$, que não é acompanhada de $\mathrm{O}_{2}$ para as mitocôndrias (através dos espaços intercelulares e do meio líquido citoplasmático); além disso, essa elevação de temperatura promove redução na solubilidade do $\mathrm{O}_{2}$ no meio aquoso celular. Isto pode ocasionar a estabilização no aumento das taxas respiratórias em temperaturas mais altas (entre $20 \mathrm{e}$ $30^{\circ} \mathrm{C}$ ), como observado para o tipo Brasil (Figura 2), que apresenta maior espessura de casca em relação ao tipo Uruguai. A menor espessura da casca do tipo Uruguai pode permitir maior difusão de $\mathrm{O}_{2}$ para o interior do fruto, comparativamente ao tipo Brasil, o que resulta em aumento gradual e contínuo nas taxas respiratórias com o aumento da temperatura.

Os valores de $\mathrm{Q}_{10}$ para a taxa respiratória foram de 3,5 e 3,4 para os tipos Brasil e Uruguai, respectivamente, com o aumento de temperatura de 0 para $30^{\circ} \mathrm{C}$ (Figura 2). Esses valores são superiores aos observados para a respiração, na mesma faixa de temperatura, em diversas espécies de frutos $\left(\mathrm{Q}_{10}=2,3\right)$ (Hardenburg et al., 1986). Altos valores de $\mathrm{Q}_{10}$ indicam grande elevação na atividade metabólica dos frutos, com o aumento na temperatura, o que resulta em menor período de armazenamento e rápida senescência pós-colheita (Wills et al., 1998). Em razão disto, frutos de goiaba-serrana requerem cuidados especiais de manejo, especialmente com relação ao resfriamento, na preservação da sua qualidade pós-colheita (Thorp \& Klein, 1987; Hoffmann et al., 1994).

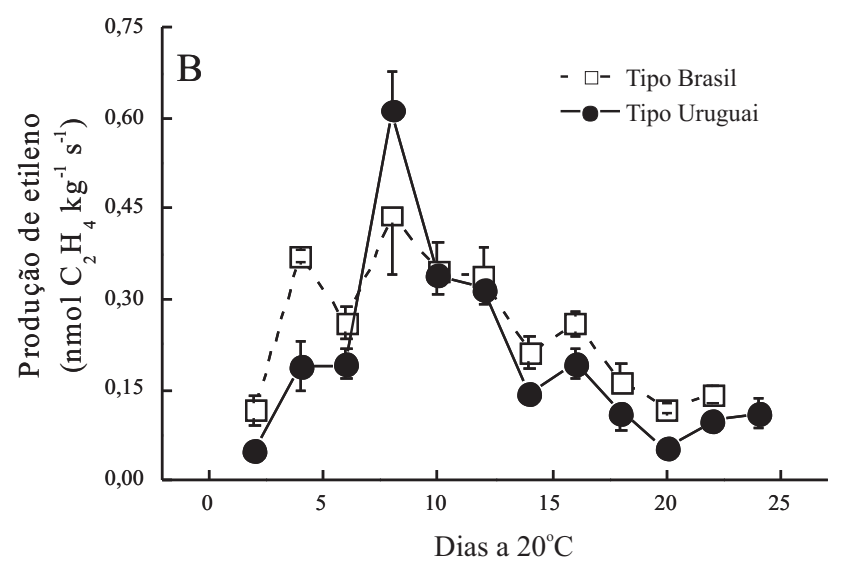
de aumento, na mesma magnitude, na taxa de difusão 
Frutos do tipo Brasil apresentaram maior alteração na cor verde da epiderme - caracterizada pela redução nos valores de $\mathrm{h}^{\circ}-$, com o aumento na temperatura, em relação aos frutos do tipo Uruguai (Figura 3). O valor de variação de $\mathrm{h}^{\circ}$ da epiderme, em função do tempo (dh\% $/ \mathrm{dt}$ ), em resposta ao aumento da temperatura, foi aproximadamente duas vezes maior em frutos do tipo Brasil, comparativamente aos do Uruguai (Figura 4 A). No entanto, frutos do tipo Uruguai mostraram grande redução no valor de L da casca, em função do tempo de armazenamento (dL/dt), com o aumento da temperatura acima de $10^{\circ} \mathrm{C}$, o mesmo fato não ocorreu com frutos do tipo Brasil (Figura 4 B). A maior redução do dL/dt, com o aumento na temperatura no tipo Uruguai, é conseqüência do escurecimento da epiderme como resultado da senescência. Esse processo foi menos marcante no tipo Brasil. Em temperaturas abaixo de $5^{\circ} \mathrm{C}$, houve ligeira redução do $\mathrm{dL} / \mathrm{dt}$ em ambos os genótipos, principalmente no tipo Uruguai. Essa redução do $\mathrm{dL} / \mathrm{dt}$, em temperaturas próximas de $0^{\circ} \mathrm{C}$, pode ter resultado no escurecimento da epiderme como conseqüência do dano por frio. Em genótipos do tipo Uruguai, cultivados na Nova Zelândia, tem sido relatado dano por frio a $0^{\circ} \mathrm{C}$, portanto, é recomendado o armazenamento a $4^{\circ} \mathrm{C}$ (Thorp \& Klein, 1987). Todavia, em frutos de goiabeira-serrana,

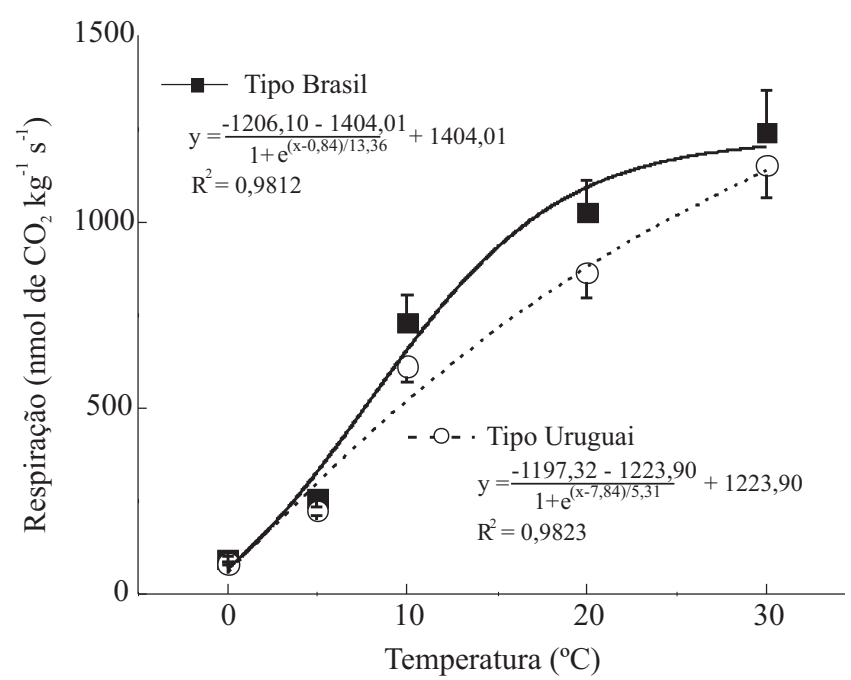

Figura 2. Taxas respiratórias de goiaba-serrana dos tipos Brasil (acesso 387) e Uruguai (acesso 454), em resposta ao aumento da temperatura. Os símbolos representam valores médios \pm erro-padrão da média $(\mathrm{n}=4)$. colhidos no Sul do Brasil e armazenados a 0 e $2^{\circ} \mathrm{C}$, em até 28 dias, seguido de dois dias à temperatura ambiente, não foi observado dano por frio (Hoffmann et al., 1994). Esses trabalhos parecem mostrar que frutos do tipo Brasil são menos sensíveis ao dano por frio do que os do tipo Uruguai, quando armazenados a temperaturas próximas de $0^{\circ} \mathrm{C}$.

O tratamento com 1-MCP retardou o amadurecimento dos frutos armazenados sob refrigeração $\left(4^{\circ} \mathrm{C}\right)$, especialmente em avaliação feita aos 30 dias (Tabela 1). $\mathrm{Na}$ avaliação efetuada aos 15 dias, houve aumento na resistência à compressão e retardamento na alteração da cor verde da epiderme (maiores valores de $\mathrm{h}^{\mathrm{o}}$ ), com o incremento nas doses de 1-MCP. Aos 30 dias de armazenamento refrigerado, o aumento nas doses de 1-MCP promoveu melhor preservação de todos os atributos de textura avaliados - força para ruptura da epiderme, força para penetração da polpa, resistência do fruto à compressão e ao corte -, firmeza de polpa e de cor da epiderme. Apenas os atributos de SS e AT não foram afetados pelo aumento na dose de 1-MCP, aos 30 dias.

A perda de consistência da polpa dos frutos é um dos processos de maturação mais sensíveis à ação do etileno (Lelièvre et al., 1997). O aumento nas doses de 1-MCP retardou as alterações de firmeza de polpa e de todos os atributos de textura, avaliados aos 30 dias de armazenamento refrigerado (Tabela 1), provavelmente em razão da redução da atividade das enzimas de degradação de parede celular, que ocorre em resposta à inibição da ação do etileno pelo 1-MCP (Watkins, 2006; Morais et al., 2008). O tratamento com 1-MCP também retarda a degradação de clorofilas (Blankenship \& Dole, 2003; Watkins, 2006) e, portanto, a perda de cor verde da epiderme (Tabela 1). Os atributos de qualidade relacionados aos teores de SS e AT não foram sensíveis ao tratamento com 1-MCP, durante o armazenamento a $4^{\circ} \mathrm{C}$ (Tabela 1), o que confirma resultados relatados por outros autores, em estudos sobre maçãs (Fan et al., 1999; Watkins et al., 2000; Argenta et al., 2001) e pêssegos (Ligouri et al., 2004; Freitas et al., 2007) tratados com o produto.

Os frutos de goiabeira-serrana apresentam elevadas taxas respiratórias e de produção de etileno e, portanto, necessitam de imediata refrigeração pós-colheita, para preservar sua qualidade. Os frutos apresentam comportamento climatérico, e seu amadurecimento é retardado pela inibição da ação do etileno, no tratamento pós-colheita com 1-MCP associado à refrigeração, e que aumenta o período de armazenamento.

Pesq. agropec. bras., Brasília, v.43, n.12, p.1683-1689, dez. 2008 

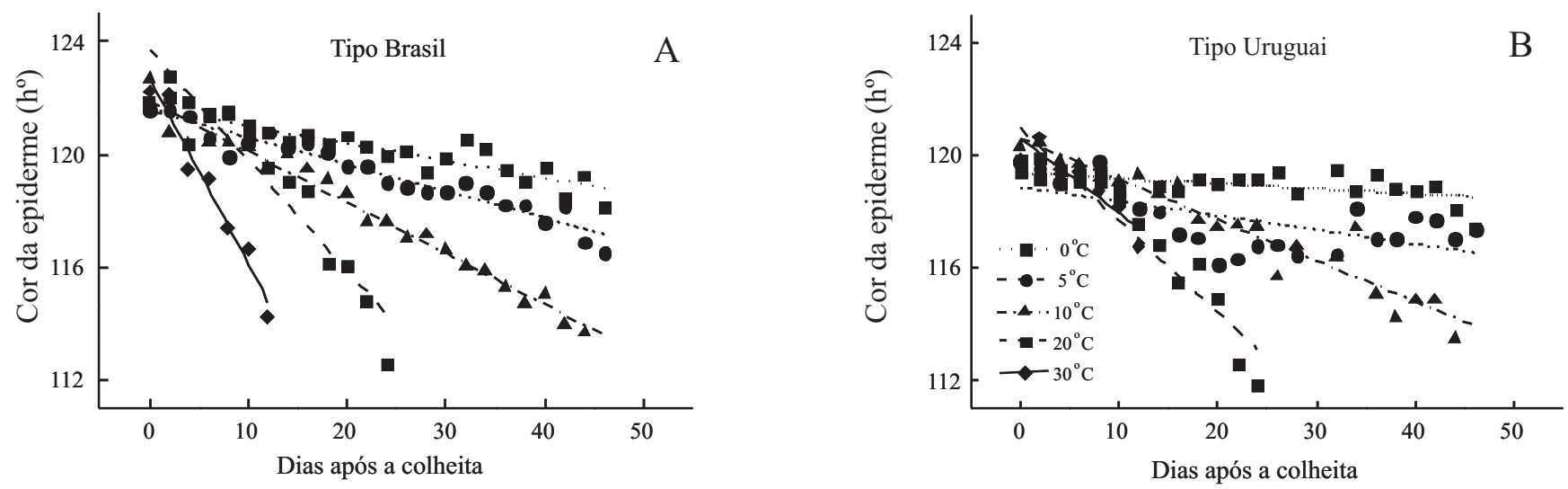

Figura 3. Alterações na cor da epiderme (ângulo 'hue', $h^{\circ}$ ) de goiaba-serrana, dos tipos Brasil (acesso 387) (A) e Uruguai (acesso 454) (B), armazenada a diferentes temperaturas.
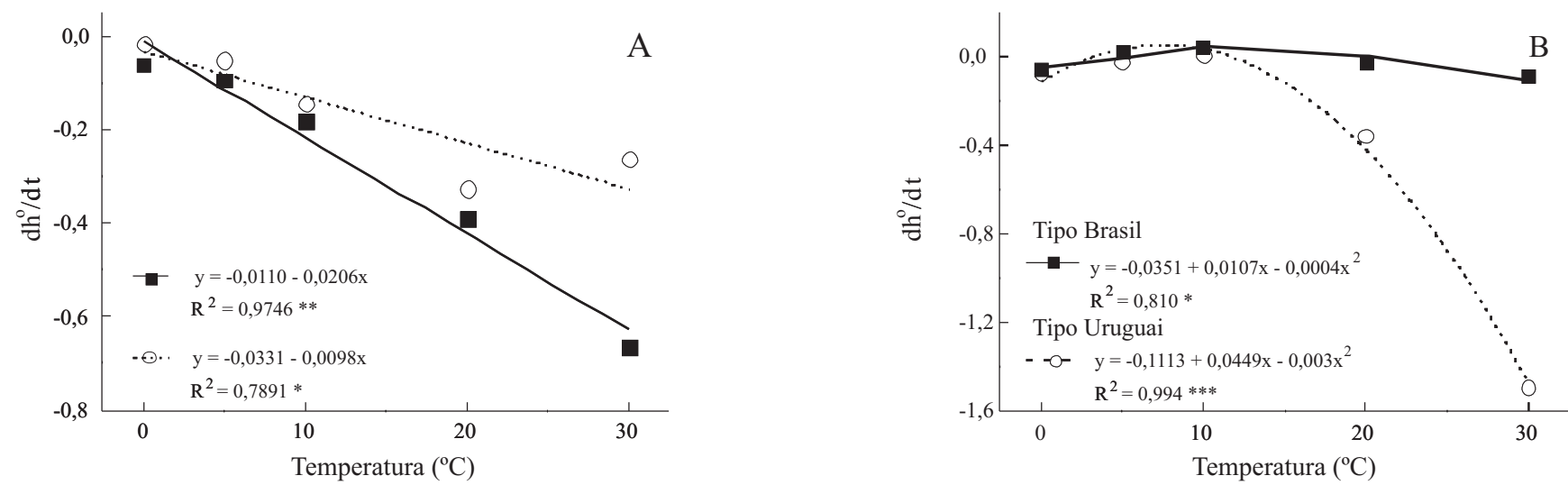

Figura 4. Alterações em função do tempo, nos atributos de ângulo 'hue' (dh\%/dt) (A) e luminosidade (dL/dt) (B), da epiderme de goiaba-serrana, dos tipos Brasil (acesso 387) e Uruguai (acesso 454), armazenada a diferentes temperaturas.

Tabela 1. Preservação da qualidade pós-colheita de frutos de goiaba-serrana do tipo Brasil (acesso 242), tratados com diferentes doses de 1-metilciclopropeno (1-MCP) e armazenados sob refrigeração $\left(4 \pm 2^{\circ} \mathrm{C} / 90 \pm 5 \%\right.$ UR) por 15 e 30 dias ${ }^{(1)}$.

\begin{tabular}{|c|c|c|c|c|c|c|c|c|}
\hline \multirow{2}{*}{$\begin{array}{l}\text { Dose de } \\
1-\mathrm{MCP} \\
(\mathrm{ppb})\end{array}$} & \multicolumn{4}{|c|}{ Atributos de textura $(\mathrm{N})$} & \multirow{2}{*}{$\begin{array}{l}\text { Cor da } \\
\text { epiderme } \\
\left(h^{\circ}\right)\end{array}$} & \multirow{2}{*}{$\begin{array}{l}\text { Firmeza } \\
(\mathrm{N})\end{array}$} & \multirow{2}{*}{$\begin{array}{c}\text { SS } \\
\left({ }^{\circ} \text { Brix }\right)\end{array}$} & \multirow{2}{*}{$\begin{array}{c}\mathrm{AT} \\
\text { (\% ácido cítrico) }\end{array}$} \\
\hline & $\begin{array}{c}\text { Força para } \\
\text { ruptura da } \\
\text { epiderme }\end{array}$ & $\begin{array}{c}\text { Força para } \\
\text { penetração da } \\
\text { polpa }\end{array}$ & $\begin{array}{l}\text { Resistência do } \\
\text { fruto à } \\
\text { compressão }\end{array}$ & $\begin{array}{l}\text { Resistência do } \\
\text { fruto ao corte }\end{array}$ & & & & \\
\hline $\begin{array}{r}0 \\
500 \\
1500\end{array}$ & $\begin{array}{r}10,15 \\
9,22 \\
10,48 \\
\end{array}$ & $\begin{array}{l}3,32 \\
3,15 \\
3,78 \\
\end{array}$ & $\begin{array}{l}64,50 \\
76,00 \\
71,19 \\
\end{array}$ & $\begin{array}{c}15 \text { dias } \\
102,60 \\
80,56 \\
84,03\end{array}$ & $\begin{array}{l}119,56 \\
120,42 \\
121,05\end{array}$ & $\begin{array}{l}68,60 \\
64,29 \\
63,99 \\
\end{array}$ & $\begin{array}{l}8,60 \\
8,27 \\
8,27 \\
\end{array}$ & $\begin{array}{l}0,15 \\
0,14 \\
0,15\end{array}$ \\
\hline Linear & $\mathrm{ns}$ & $\mathrm{ns}$ & $\mathrm{ns}$ & ns & $*$ & $\mathrm{~ns}$ & ns & $\mathrm{ns}$ \\
\hline Quadrático & ns & ns & $*$ & ns & ns & ns & ns & ns \\
\hline CV $(\%)$ & 11,12 & 15,62 & 8,90 & 16,38 & 0,74 & 11,57 & 7,87 & 12,23 \\
\hline & & & & 30 dias & & & & \\
\hline 0 & 9,18 & 3,36 & 43,43 & 94,50 & 118,75 & 48,28 & 8,87 & 0,14 \\
\hline 500 & 9,92 & 3,59 & 50,36 & 111,95 & 120,32 & 55,40 & 9,13 & 0,13 \\
\hline 1500 & 11,50 & 5,11 & 57,02 & 143,82 & 120,71 & 60,69 & 8,67 & 0,13 \\
\hline Linear & $*$ & $* *$ & $*$ & $* * *$ & $*$ & $*$ & ns & $\mathrm{ns}$ \\
\hline Quadrático & $\mathrm{ns}$ & $\mathrm{ns}$ & $\mathrm{ns}$ & $\mathrm{ns}$ & $\mathrm{ns}$ & $\mathrm{ns}$ & ns & $\mathrm{ns}$ \\
\hline CV $(\%)$ & 14,19 & 24,08 & 15,74 & 19,70 & 1,00 & 12,48 & 6,85 & 7,92 \\
\hline
\end{tabular}

(1)Valores médios na colheita: ângulo ‘hue' ( $\mathrm{h}^{\circ}$ ), 120,78; firmeza, 64,19 N; sólidos solúveis (SS), 8,47ºrix; e acidez titulável (AT), 0,38\% de ácido cítrico; dados analisados por meio de contrastes ortogonais polinomiais. ns ${ }^{\text {Não-significativo. } *, * *} \mathrm{e}^{* * *}$ Significativo a 5,1 e $0,1 \%$ de probabilidade, respectivamente. 


\section{Conclusões}

1. Goiabas-serranas dos tipos Brasil e Uruguai apresentam similaridade no padrão climatérico de respiração e produção de etileno a $20^{\circ} \mathrm{C}$.

2. A taxa respiratória aumenta em ambos os genótipos, com o aumento na temperatura de 0 a $30^{\circ} \mathrm{C}$, com coeficiente metabólico de aproximadamente 3,5.

3. Com o aumento na temperatura, há maior alteração na cor verde da epiderme em frutos do tipo Brasil, e maior escurecimento da epiderme nos do tipo Uruguai.

4. Frutos tratados com 1-metilciclopropeno e armazenados a $4^{\circ} \mathrm{C}$ apresentam retardamento no amadurecimento.

\section{Agradecimentos}

Ao Conselho Nacional de Desenvolvimento Científico e Tecnológico, por concessão de bolsas.

\section{Referências}

ARGENTA, L.C.; MATTHEIS, J.; FAN, X. Retardamento da maturação de maçãs 'Fuji' pelo tratamento com 1-MCP e manejo da temperatura. Revista Brasileira de Fruticultura, v.23, p.270-273, 2001.

BARNI, E.J.; DUCROQUET, J.P.H.J.; SILVA, M.C.; BEPPLER NETO, R.; PRESSER, R.F. Potencial de mercado para goiabeira-serrana catarinense. Florianópolis: Epagri, 2004. 48p. (Documento, 212).

BASILE, A.; VUOTTO, M.L.; VIOLANTE, U.; SORBO, S.; MARTONE, G.; ASTALDOCOBIANCHI, R. Antibacterial activity in Actinidia chinensis, Feijoa sellowiana and Aberia caffra. International Journal of Antimicrobial Agents, v.8, p.199-203, 1997.

BLANKENSHIP, S.M.; DOLE, J.M. 1-Methylcyclopropene: a review. Postharvest Biology and Technology, v.28, p.1-25, 2003.

DEGENHARDT, J.; DUCROQUET, J.P.H.J.; GUERRA, M.P.; NODARI, R.O. Avaliação fenotípica de características de frutos em duas famílias de meios-irmãos de goiabeira-serrana (Acca sellowiana Berg.) de um pomar comercial em São Joaquim, SC. Revista Brasileira de Fruticultura, v.25, p.475-479, 2003.

DUCROQUET, J.P.H.J.; HICKEL, E.R.; NODARI, R.O. Goiabeira-serrana (Feijoa sellowiana Berg). Jaboticabal: Funef, 2000. 66p. (Série Frutas Nativas, 5).

FAN, X.T.; BLANKENSHIP, S.M.; MATTHEIS, J.P. 1-Methylcyclopropene inhibits apple ripening. Journal of American Society of Horticultural Science, v.124, p.690-695, 1999.

FREITAS, S.T. de; SAUTTER, C.; SILVEIRA, A.C.; BRACKMANN, A. Evaluación del efecto de la aplicación de 1-MCP y la conservación en atmósfera controlada sobre la calidad poscosecha de duraznos en dos estados de madurez. Agrociencia Montevideo, v.11, p.67-72, 2007.
HARDENBURG, R.E.; WATADA, A.E.; WANG, C.Y. The commercial storage of fruits, vegetables and florist and nursery stocks. Washington: Department of Agriculture, Agricultural Research Service, 1986. 136p. (Agricultural Handbook, 66).

HOFFMANN,A.; NACHTIGAL, J.C.; KLUGE, R.A.; BILHALVA, A.B. Influência da temperatura e do polietileno no armazenamento de frutos de goiabeira-serrana (Feijoa sellowiana Berg.). Scientia Agricola, v.51, p.563-568, 1994.

LEGRAND, C.D.; KLEIN, R.M. Mirtáceas. In: REITZ, P.R. Flora Ilustrada Catarinense. Itajaí: Herbário Barbosa Rodrigues, 1977. p.573-730.

LELIÈVRE, J.M.; LATCHÉ, A.; JONES, B.; BOUZAYEN, M.; PECH, J.Z. Ethylene and fruit ripening. Physiologia Plantarum, v.101, p.727-739, 1997.

LIGOURI, G.; WEKSLER, A.; ZUTAHI, Y.; LURIE, S.; KOSTO, I. Effect of 1-methylcyclopropene on ripening of melting flesh peaches and nectarines. Postharvest Biology and Technology, v.31, p.263-268, 2004.

MATTOS, J.R. Goiabeira-serrana: fruteiras nativas do Brasil. 2.ed. Porto Alegre: Ceue, 1990. 120p.

MORAIS, P.L.D. de; LIMA, L.C. de O.; MIRANDA, M.R.A. de; ALVES, J.D.; ALVES, R.E.; SILVA, J.D. Enzyme activities and pectin breakdown of sapodilla submitted to 1-methylcyclopropene. Pesquisa Agropecuária Brasileira, v.43, p.15-20, 2008.

SAS INSTITUTE. Getting started with the SAS learning edition. Cary: SAS Institute, 2002. 200p.

TAIZ, L.; ZEIGER, E. Plant physiology. $3^{\text {rd }}$ ed. Sunderland: Sinauer Associates, 2002. 690p.

THORP, T.G. DSIR's feijoa breeding programme goes to South America. The Orchardist of New Zealand, v.61, p.213-215, 1988.

THORP, T.G.; KLEIN, J.D. Export feijoas: post-harvest handling and storage techniques to maintain optimum fruit quality. The Orchardist of New Zealand, v.60, p.164-166, 1987.

VUOTTO, M.L.; BASILE, A.; MOSCATIELLO, V.; DE SOLE, P.; CASTALDO-COBIANCHI, R.; LAGHI, E.; IELPO, M.T.L. Antimicrobial and antioxidant activities of Feijoa sellowiana fruit. International Journal of Antimicrobial Agents, v.13, p.197-201, 2000 .

WATKINS, C.B. The use of 1-methylcyclopropene (1-MCP) on fruits and vegetables. Biotechnology Advances, v.24, p.389-409, 2006.

WATKINS, C.B.; NOCK, J.F.; WHITAKER, B.D. Response of early, mid and late season apple cultivars to postharvest application of 1-methylcyclopropene (1-MCP) under air and controlled atmosphere storage conditions. Postharvest Biology and Technology, v.19, p.17-32, 2000.

WILLS, R.H.; McGLASSON, W.B.; GRAHAM, D.; JOYCE, D. Postharvest: an introduction to the physiology and handling of fruit, vegetables and ornamentals. $4^{\text {th }}$ ed. New York: CAB International, 1998. 262p.

$\overline{\text { Recebido em } 16 \text { de setembro de } 2008 \text { e aprovado em } 27 \text { de novembro de } 2008}$ 